\title{
Improving the quality of cause of death data for public health policy: are all 'garbage' codes equally problematic?
}

\author{
Mohsen Naghavi ${ }^{1}$, Nicola Richards², Hafiz Chowdhury², James Eynstone-Hinkins ${ }^{3}$, Elisabeth Franca ${ }^{4}$, \\ Michael Hegnauer ${ }^{5}$, Ardeshir Khosravi ${ }^{6}$, Lauren Moran ${ }^{3}$, Lene Mikkelsen ${ }^{2^{*}}$ and Alan D. Lopez ${ }^{2}$
}

Keywords: Mortality, Cause of death, Garbage codes, Unusable and insufficiently specified codes, ICD-10, III-defined codes, Policy, Planning

\section{Background}

All countries need accurate and timely mortality statistics to inform health and social policy debates and to monitor progress towards national and global health development goals. In many countries, however, civil registration and vital statistics (CRVS) systems are poorly developed. Consequently, the statistics they produce are not fit for purpose. In part, this arises because the physicians certifying cause of death (COD) have either not been adequately trained in how to complete a death certificate according to the current International Statistical Classification of Diseases - Version 10 (ICD-10) [1], or they fail to appreciate the public health importance of what is often perceived as a largely administrative task [2]. This can be reinforced by cultural attitudes and perceptions among hospital administrators, who are generally unaware of the critical contribution that accurate medical certification of CODs makes to generating essential public health intelligence that can be used for planning.

Unsurprisingly, these system deficiencies usually result in a high proportion of CODs being assigned to 'garbage' codes [3]. These have little or no public health value because they are too vague, are an immediate or intermediate COD, or are impossible as an underlying cause of death (UCOD). For example, septicaemia is often chosen as the underlying or precipitating COD when it is, in fact, the immediate cause arising from a many possible UCODs including communicable or non-communicable diseases, or an injury [3]. Prevention strategies would

\footnotetext{
*Correspondence: I.mikkelsen@unimelb.edu.au

${ }^{2}$ Melbourne School of Population and Global Health, University of

Melbourne, 207 Bouverie Street, Carlton, VIC 3053, Australia

Full list of author information is available at the end of the article
}

differ markedly depending on the UCOD; hence the importance of correct certification.

Garbage codes bias a country's true pattern of mortality. Studies of the quality of mortality statistics carried out in Thailand [4], Sri Lanka [5], and Iran [6], for example, have repeatedly found that the population's likely true mortality pattern was considerably different from the pattern reported by the CRVS system. These discrepancies have been largely attributed to physicians' extensive use of garbage codes.

\section{Towards a more useful public health classification of garbage codes}

The rationale for identifying garbage codes is that, by doing so, certifying physicians and coders can be encouraged and trained to avoid unspecific ICD codes that are unlikely to be useful in guiding disease and injury control strategies. Specifically, national health planners must understand which misdiagnoses have the greatest impact on policy decions. Rather than classifying garbage codes according to the type of error (see Naghavi et al. [3]), an alternative classification is therefore needed, based on the severity of the impact that particular garbage codes might have in seriously misinforming public policy.

Accordingly, we have adapted the classification of garbage codes used by the Global Burden of Disease study to guide efforts to improve CRVS data quality. We focus more on the likely policy implications of various types of misdiagnosis of the true UCOD. The four distinct levels of garbage codes are defined as:

- Level 1 (very high) - codes with serious policy implications. These are causes (e.g. septicaemia) for 
which the true UCOD might belong to any one of three broad cause groups: communicable or noncommunicable diseases, or injuries. We simply don't know. Such errors potentially grossly misinform understanding of the extent of an epidemiological transition in a population.

- Level 2 (high) - codes with substantial policy implications. These are causes for which the true UCOD is likely to belong to one, or at most two, of the three broad groups, (e.g., 'essential (primary) hypertension'). While not greatly altering the understanding of the broad composition of mortality in a population, these codes might considerably affect the comparative importance of leading causes within broad disease categories.

- Level 3 (medium) - codes with important policy implications. These are causes for which the true underlying UCOD is likely to be within the same ICD chapter. For instance, 'unspecified cancer' still identifies the death as being attributed to cancer, thus has some policy value, although greater type (site) specificity is required because different strategies are applied for different sites of cancer (e.g. breast versus lung).

- Level 4 (low) - codes with limited policy implications. These are diagnoses for which the true UCOD is likely to be confined to a single disease or injury category (e.g. unspecified stroke would still be assigned as a stroke death). The implications of unusable causes classified at this level will therefore, generally, be much less important for public policy.

To better focus data quality improvement efforts, this new classification only identifies the garbage codes that are truly unhelpful for policy and are used frequently by physicians to certify deaths; namely, levels $1-3$. This excludes, for example, 'unspecified pneumonia', which although considered a garbage code in the Global Burden of Disease study, given its relevance for research and technology development [4], can be ignored in this public health oriented framework since we believe it provides sufficient information to guide public health interventions. Morever, any public health-orientated garbage code classification must be realistic about countries' diagnostic capacity at different levels of development. For example, to reliably distinguish between haemorrhagic and ischaemic stroke, a computed tomography scan or magnetic resonance image is usually necessary - technologies that are not widely available in low- and middle-income countries.

\section{Conclusion}

Implications for mortality data systems

To help countries identify the pattern and extent of garbage coding in their COD data, this new typology of garbage codes has been included in the data quality assessment tool, Analysis of Causes of National Deaths for Action (ANACONDA) developed by the University of Melbourne's Bloomberg Philanthropies Data for Health Initiative in partnership with the Swiss Tropical and Public Health Institute at the University of Basel [7].

This tool allows countries to identify not only the relative importance of different categories of garbage codes, but also the ICD codes that are most commonly misused within each of these three levels. Strategies to improve COD data quality in hospitals should address the most commonly used garbage codes from all categories. However, clearly, greater emphasis should be given to reducing the frequency of those codes, which have the greatest potential to seriously distort the evidence-base for public health policy designed to reduce premature mortality.

\section{Abbreviations}

COD: Cause of death; CRVS: Civil registration and vital statistics; ICD: International Statistical Classification of Diseases and Related Health Problems; UCOD: Underlying cause of death

\section{Acknowledgements \\ This paper is based on a technical meeting held at the Melbourne School of Population and Global Health, University of Melbourne, on 27-28 February 2018. The authors acknowledge inputs at the meeting from Saman Gamage, Deirdre Mclaughlin, Tim Moore, Rasika Rampatige and lan Riley, University of Melbourne; Pamela Groenewald, South Africa Medical Research Council; and Jomilynn Rebenal, Ministry of Health, the Philippines.}

\section{Authors' contributions}

$M N, A D L$, and LM conceptualised earlier versions of the classification and led the workshop from which this manuscript is derived. NR drafted first version of the manuscript. LM and ADL finalised the manuscript. MN, $H C, J E-H, E F$, $\mathrm{MH}, \mathrm{AK}$ and LMo provided comments on the draft manuscript. All authors read and approved the final version of the manuscript.

\section{Funding}

This study was funded by an award from Bloomberg Philanthropies to the University of Melbourne to support the Data for Health Initiative. The funders had no role in study design, data collection and analysis, decision to publish, or preparation of the manuscript.

Availability of data and materials

Not applicable.

Ethics approval and consent to participate

Not applicable.

Consent for publication

Not applicable.

Competing interests

The authors declare that they have no competing interests.

\section{Author details}

${ }^{1}$ Institute of Health Metrics and Evaluation, University of Washington, 2301 5th Ave, Seattle, WA 98121, USA. ${ }^{2}$ Melbourne School of Population and Global Health, University of Melbourne, 207 Bouverie Street, Carlton, VIC 3053, Australia. ${ }^{3}$ Australian Bureau of Statistics, 295 Ann Street, Brisbane, QLD 4000, Australia. ${ }^{4}$ University of Minas Gerais, Belo Horizonte, Minas Gerias 31270-901, Brazil. ${ }^{5}$ Swiss Tropical and Public Health Institute, University of Basel, Basel, Switzerland. ${ }^{6}$ Ministry of Health and Medical Education, District 2, Eyvanak Blvd, Tehran, Iran. 
Received: 3 February 2020 Accepted: 11 February 2020

Published online: 09 March 2020

\section{References}

1. Rampatige R, Mikkelsen L, Hernandez B, Riley I, Lopez A. Systematic review of statistics on causes of deaths in hospitals: strengthening the evidence for policy-makers. Bull World Health Org. 2014;92:807-16.

2. Ahern RM, Lozano R, Naghavi M, Foreman K, Gakidou E, Murray CJL. Improving the public health utility of global cardiovascular mortality data: the rise of ischemic heart disease. Pop Health Metrics. 2011;9:1.

3. Naghavi M, Makela S, Foreman K, O'Brien J, Pourmalek F, Lozano R. Algorithms for enhancing public health utility of national causes-of-death data. Pop Health Metrics. 2010;8:9-22.

4. Pattaraarchachai J, Rao C, Polprasert W, Porapakkam Y, Pao-in W, Wansa S, et al. Cause-specific mortality patterns among hospital deaths in Thailand: validating routine death certification. Pop Health Metrics. 2010;8:12-23.

5. Rampatige R, Gamage S, Peirkis S, Lopez AD. Assessing the reliability of causes of death reported by the vital registration system in Sri Lanka: medical records review in Colombo. Health Inf Manage J. 2013;42(3):20-8.

6. Khosravi A, Rao C, Naghavi M, Taylor R, Jafari N, Lopez AD. Impact of misclassification on measures of cardiovascular disease mortality in the Islamic Republic of Iran: a cross-sectional study. Bull World Health Org. 2008; 86:688-96.

7. Mikkelsen L, Moesgaard K, Hegnauer M, Lopez AD. ANACONDA: A new tool to improve mortality and cause of death data. BMC Medicine. 2020. https:// doi.org/10.1186/s12916-020-01521-0.

\section{Publisher's Note}

Springer Nature remains neutral with regard to jurisdictional claims in published maps and institutional affiliations.

Ready to submit your research? Choose BMC and benefit from:

- fast, convenient online submission

- thorough peer review by experienced researchers in your field

- rapid publication on acceptance

- support for research data, including large and complex data types

- gold Open Access which fosters wider collaboration and increased citations

- maximum visibility for your research: over $100 \mathrm{M}$ website views per year

At $\mathrm{BMC}$, research is always in progress.

Learn more biomedcentral.com/submissions 